\title{
PRODUTOS DA AGRICULTURA FAMILIAR NA ALIMENTAÇÃO ESCOLAR DO MUNICÍPIO DE CURUÇÁ-PA: DESAFIOS E PERSPECTIVAS
}

\author{
Maiara dos Santos Ramos ${ }^{1}$; Rosana Quaresma Maneschy' ${ }^{2}$ Jaqueline Fontel de Queiroz ${ }^{3}$; \\ Maria de Nazaré Caetana Marques ${ }^{4}$; Tahnity Haarad Moura Chaves ${ }^{5}$. \\ 1 Universidade Federal do Pará (UFPA), Belém, Pará, Brasil, maiara.stramos@gmail.com \\ ${ }^{2}$ Núcleo de Meio Ambiente (NUMA) da UFPA, Belém, Pará, Brasil, romaneschy@ufpa.br \\ ${ }^{3}$ Bolsista PIBIC/UFPA, Belém, Pará, Brasil, jaqueline.fontel07@gmail.com \\ ${ }^{4}$ Graduanda em Ciências Econômicas UFPA, Belém, Pará, Brasil, caetana.maria@yahoo.com.br \\ ${ }^{5}$ Mestranda do PPGEDAM/NUMA/UFPA, Belém, Pará, Brasil, tahnityhaarad@gmail.com
}

RESUMO: O Programa Nacional de Alimentação Escolar (PNAE) maior programa de alimentação no Brasil, ampliado em 2009 tem por objetivo fornecer produtos da agricultura familiar para merenda escolar no âmbito estadual e municipal beneficiando 13 milhões de escolas em todo país. O objetivo do trabalho foi diagnosticar e analisar os fatores limitantes para a participação dos agricultores familiares de Curuçá à comercialização de produtos para a alimentação escolar. Foram realizados levantamento junto a Empresa de Assistência Técnica e Extensão Rural (EMATER-PA) secretaria de alimentação escolar e secretaria e educação para a obtenção de dados referentes aos números de escola abastecida pela agricultura familiar que fazem parte da região.

PALAVRAS-CHAVE: Pequenos proprietários rurais; Merenda escolar; Desenvolvimento local.

\section{FAMILY'S FARMING PRODUCTS IN SCHOOL FEEDING OF CURUÇÁ-PA MUNICIPALITY: CHALLENGES AND PERSPECTIVES}

\begin{abstract}
The National School Feeding Program (PNAE) largest feeding program in Brazil, increased in 2009 aims to provide products from family farming for state and municipal school lunches benefiting 13 million schools across the country. The objective of the study was to diagnose and analyze the limiting factors for the participation of the family farmers of Curuçá to the commercialization of products for school feeding. A survey was carried out with the Technical Assistance and Rural Extension Company (EMATER-PA), a school feeding secretariat and a secretariat and education to obtain data on the numbers of schools supplied by family farms that are part of the region.
\end{abstract}

KEY-WORDS: Small landowners; School lunch; Local Development. 


\section{PRODUCTOS DE LA AGRICULTURA FAMILIAR EN LA ALIMENTACIÓN ESCOLAR DEL MUNICIPIO DE CURUÇÁ-PA: DESAFÍOS Y PERSPECTIVAS}

RESUMEN: El Programa Nacional de Alimentación Escolar (PNAE) mayor programa de alimentación en Brasil, ampliado en 2009 tiene por objetivo proporcionar productos de la agricultura familiar para merienda escolar en el ámbito estadual y municipal, beneficiando a 13 millones de escuelas en todo el país. El objetivo del trabajo fue diagnosticar y analizar los factores limitantes para la participación de los agricultores familiares de Curuçá a la comercialización de productos para la alimentación escolar. Se realizaron levantamientos a la Empresa de Asistencia Técnica y Extensión Rural (EMATER-PA) secretaría de alimentación escolar y secretaría y educación para la obtención de datos referentes a los números de escuela abastecida por la agricultura familiar que forman parte de la región.

PALABRAS CLAVE: Pequeños propietarios rurales; Merenda escolar; Desarrollo local.

\section{INTRODUÇÃO}

No Brasil, dentre as políticas públicas que integram o Sistema Nacional de Segurança Alimentar Nutricional está o Programa Nacional de Merenda Escolar (PNAE) vinculado ao Ministério do Desenvolvimento Social e Combate à Fome, onde diversos estudos recentes têm apontado na sua trajetória histórica avanços em relação a seus objetivos, gestão, execução, abrangência e articulação com outros setores além da educação, tornando-se um dos maiores programas de alimentação escolar do mundo (VILA, 2013; CONSEA, 2010 apud TÉO; MONTEIRO, 2012).

Os recursos para o provimento desse programa provêm do Tesouro Nacional de Desenvolvimento da Educação (FNDE). Cabe efetuar a transferência dos recursos aos estados e municípios, que têm a obrigação de dar suporte técnico e administrativo, mas também são desafiados a complementar e ampliar os recursos provindos do Governo Federal. Com aprovação da Lei 11.947/2009, este programa se reveste de uma importância estratégica para os agricultores familiares, pois a lei obriga o gestor público a adquirir da agricultura familiar local, pelo menos, 30\% de toda a alimentação consumida nas escolas. (AÇ̃̃O FOME ZERO, 2013).

O PNAE tem caráter suplementar, como prevê o artigo 208, inciso IV e VII, da Construção Federal, quando coloca 
que o dever do Estado (ou seja, das três esferas governamentais: União, estados e municípios) com a educação é efetivado mediante a garantia de "atendimento em creche e pré-escola ás crianças de erro a seis anos de idade" (inciso IV) e "atendimento ao educando no ensino fundamental, através de programas suplementares de material didáticoescolar, transporte, alimentação e assistência à saúde" (inciso VII). (BRASIL, 1988).

Os recursos do PNAE destinam-se à compra de alimentos pelas secretarias de Educação dos estados e do Distrito Federal e pelos municípios, o repasse é feito diretamente aos estados e municípios, com base no censo de 2010 realizado no ano anterior ao do atendimento. (AÇÃO FOME ZERO, 2013)

Em 1954, o Programa Nacional de Alimentação Escolar (PNAE) foi criado, atendia algumas escolas do estado do Nordeste sobe responsabilidade da Comissão Nacional de Alimentação (CNA), que agia sobre a autonomia do Ministério da Educação e Saúde Pública (MESP) em 1953. A partir de 1955 vinculou-se ao Ministério da Educação e Cultural (MEC).

O período de 1970 até o final da década de 1980 foi marcado pela ascensão e declínio dos alimentos formulados introduzidos na alimentação escolar. No início da década de 1970, a ajudar alimentar internacional foi se escasseando, o que contribuiu para a instalação das primeiras indústrias alimentícia brasileiras com o fim de atender à demanda. Porém, os cardápios eram pobres em qualidade e os indicadores de quantidade per capita/ano eram insuficientes para dimensionar as necessidades nutricionais dos alunos (SPINELLI; CANESQUI, 2002).

Em 1988 a alimentação escolar passou a ser direito constitucional dos estudantes e considerada umas das estratégias de Segurança Alimentar e Nutricional (SAN), a partir da Lei Federal no 11.947 e da Resolução no 38/Fundo Nacional de Desenvolvimento da Educação (FNDE) promulgadas em julho de 2009, o Programa Nacional de Alimentação Escolar (PNAE) é o mais antigo programa social do Governo Federal na área de educação e é o maior 
programa de alimentação em atividade no Brasil.

Segundo Carvalho e Castro (2009, p.5)

"A alimentação escolar envolve aspectos cultural-territoriais; interações socioeconômicas ambientais; político-institucionais; de respeito ao ciclo da natureza de ofertar alimentos para atender á necessidade básica do indivíduo de não sentir fome; entre outros, a fim de promover a Segurança Alimentar e Nutricional (SAN) e o direito à Alimentação Adequada (DHAA)".

A partir da descentralização em 1994 pela Lei 8.913 o Programa, permitiu racionalizar a logística e os custos de distribuição dos produtos, a descentralização foi um dos grandes avanços, proporcionando uma merenda escolar de acordo com o hábito alimentar da população nas diferentes localidades, contribuindo não só para hábitos alimentares mais saudáveis, mas também para o melhor desempenho escolar e para o desenvolvimento local regional.

Diariamente são servidas cerca de 37 milhões de refeições da merenda escolar, FNDE faz os repasses de verbas provenientes do governo federal para a alimentação escolar dos estados e município, com base no número de alunos matriculados na educação básica. Uma das diretrizes estipula que, no mínimo, trinta por cento (30\%) do total destes recursos sejam destinados à compra de alimentos, preferencialmente orgânicos, produzidos pela agricultura familiar (AF), no local, regional e nacional. O programa, a partir destas diretrizes, tornou-se um importante segmento institucional para aquisição de alimentos da agricultura familiar.

O estímulo e o apoio à agricultura familiar têm se mostrado relevantes para a formulação e a implementação de ações municipais de Segurança Alimentar Nacional (SAN) e de desenvolvimento local, que visem promover o Direito Humano à Alimentação Adequada (DHAA).

Atualmente a base de cálculo do valor financeiro repassado pela União a estados e município é feito de acordo com o número de alunos matriculados no ano anterior, ou seja, os recursos da merenda de 2017 são calculados de acordo com o número de alunos matriculados em 2016. O número de alunos será multiplicado 
pelos dias letivos e pelo valor per capita da alimentação escolar, e com base no registro no Censo Escolar. O Programa é fiscalizado e acompanhado diretamente pela sociedade, por meio do Conselhos de Alimentação Escolar (CAE), pelo FNDE, pelo Tribunal de Contas da União, pela Controladoria Geral da União (CGU) e pelo Ministério Público.

No cenário nacional a agricultura familiar em geral enfrenta várias limitações ao desenvolvimento de suas práticas, bem como ao seu desenvolvimento sustentável, e para os agricultores familiares do município de Curuçá, não é diferente. Assim surgiu a problemática desse trabalho, quais seriam os fatores limitantes à participação dos agricultores na comercialização para a alimentação escolar? Na busca por respostas, investigaram-se então os fatores limitantes, com vistas a análises para solução adequada.

A abordagem justifica-se pela necessidade de promover condições para participação da agricultura familiar comercializar seus produtos agrícolas no município de Curuçá, possibilitando perspectivas de desenvolvimento sustentável local. Entretanto, para que isso ocorra, entre outras se faz necessário conhecer os fatores limitantes de produtos adquiridos pelas escolas no PNAE, por considerar-se esta, uma oportunidade de desenvolvimento não só para os agricultores familiares locais, mas também para o município. Também é possível registrar possibilidades de ampliar a ações locais em prol do desenvolvimento sustentável na agricultura familiar, dessa forma contribuindo para a valorização da agricultura familiar como geradora de qualidade de vida.

O PNAE em um modo geral é um grande incentivador da agricultura familiar, pois se trata de um meio de comercialização que garante aos agricultores familiares o escoamento e maior valorização de seus produtos através da venda direta. Assim, a pesquisa teve por objetivo diagnosticar e analisar os fatores limitantes à participação dos agricultores familiares de Curuçá à comercialização de produtos para a alimentação escolar. A fim de subsidiar os gestores públicos municipais e agricultores familiares com informações 
atuais e relevantes sobre os produtos da agricultura familiar auxiliando a elaboração de políticas públicas locais.

\section{MATERIAL E MÉTODOS}

Para o estudo de caso proposto, adotou-se a pesquisa de campo como procedimento. Tal método, segundo (FONSECA 2002 apud GRHARDT; SIVEIRA, 2009 p.37), caracteriza-se pelas investigações em que "além da pesquisa bibliográfica e/ou documental, se realiza coleta de dados junto a pessoas com o recurso de diferentes tipos de pesquisa [...]". Para contextualizar o Programa Nacional de Alimentação Escolar, foram utilizadas pesquisas eletrônicas no portal da Fundação Nacional de Desenvolvimento e Educação (FNDE).
A escolha desse município se deu pela disposição dos seus gestores em incentivar e adquirir produtos da agricultura familiar local e pela baixa participação dos agricultores ao PNAE (Programa Nacional de Alimentação Escolar). Foram realizadas entrevista entre dois grupos, sendo, um grupo de gestores/servidores públicos (Quadro 1) e outro grupo de agricultores da Associação de Produtores e Produtoras de Acaputeua (Quadro 2). Contabilizando os informantes (03 produtores) e 4 servidores públicos que atuam na Secretaria Municipal de Educação, Secretaria Municipal de Agricultura e Meio Ambiente, EMATER, Conselho de Alimentação Escolar).

Quadro 1. Entrevistados da Gestão do Município de Curuçá - PA.

\begin{tabular}{|l|l|l|l|}
\hline Código & Função & Cargo & Instituição \\
\hline Servidor 1 & Extensionista rural & Assistência Técnica & EMATER \\
\hline Gestor 1 & Secretário & Secretário de Agricultura & Prefeitura Municipal \\
\hline Servidor 2 & Nutricionista & Técnica & Prefeitura Municipal \\
\hline
\end{tabular}

Quadro 2. Entrevistados da Associação dos Produtores e Produtoras de Acaputeua - PA.

\begin{tabular}{|l|c|c|}
\hline Código & Associado & DAP* \\
\hline Agricultor 1 & SIM & SIM \\
\hline Agricultor 2 & SIM & SIM \\
\hline Agricultor 3 & SIM & SIM \\
\hline
\end{tabular}

*DAP: Declaração de Aptidão ao Pronaf. 
Também foram levantados dados secundários no banco de dados FNDE (número de alunos atendidos pelos alimentos da agricultura familiar local), IBGE (dados do município de Curuçá...) IDESP (dados da agricultura familiar no município, produtos, quantidades...) e FNDE (valores repassados ao município). Objetivando compreender tanto os fatores limitantes à participação dos agricultores familiares à comercialização para a alimentação escolar, quantas às perspectivas e potencialidades para a entrega dos produtos para a alimentação escolar.

O município de Curuçá à Microrregião do Salgado, mesorregião Nordeste, no Norte do Brasil, distante a 136 Km de Belém do Pará (Figura 1). Conforme os dados do IBGE, o município de Curuçá possui uma área territorial de $672,675 \mathrm{~km}^{2}$. Com uma população de 34.490 habitantes (censo de 2010). O território Curuçaense está inserido na exuberante paisagem da Amazônia Brasileira.
Hoje a população vive basicamente da pesca, pecuária, comércio e da agricultura, o município é um dos mais promissores polos turísticos do Estado e vive a expectativas da construção do Porto do Espadarte pela Vale. O Município possui 08 distritos (Vilas: Lauro Sodré, Ponta de Ramos, Araquaim, Murajá, Mutuca, Boa vista do Iririteua, Nazaré do Mocajuba e a povoação São João do abade, mais 62 localidades rurais distribuídas ao desses distritos, das quais 23 localiza-se nas regiões dos rios e várzeas, e 39 estão na zona do planalto. A área urbana possui 08 bairros.

A cobertura vegetal original (formada pela floresta primitiva) foi removida, em consequência, dos desmatamentos ocorridos de forma intensiva e extensiva, para o plantio de espécies florestal do Município é formado por Florestas secundarias. É importante também a presença de florestas de Mangue ou Manguezais, que ocupam as porções litorâneas e semi-litorâneas, onde existe influência da salinidade da água do mar (IBGE, 2010). 
Figura 1. Localização do Município de Curuçá.

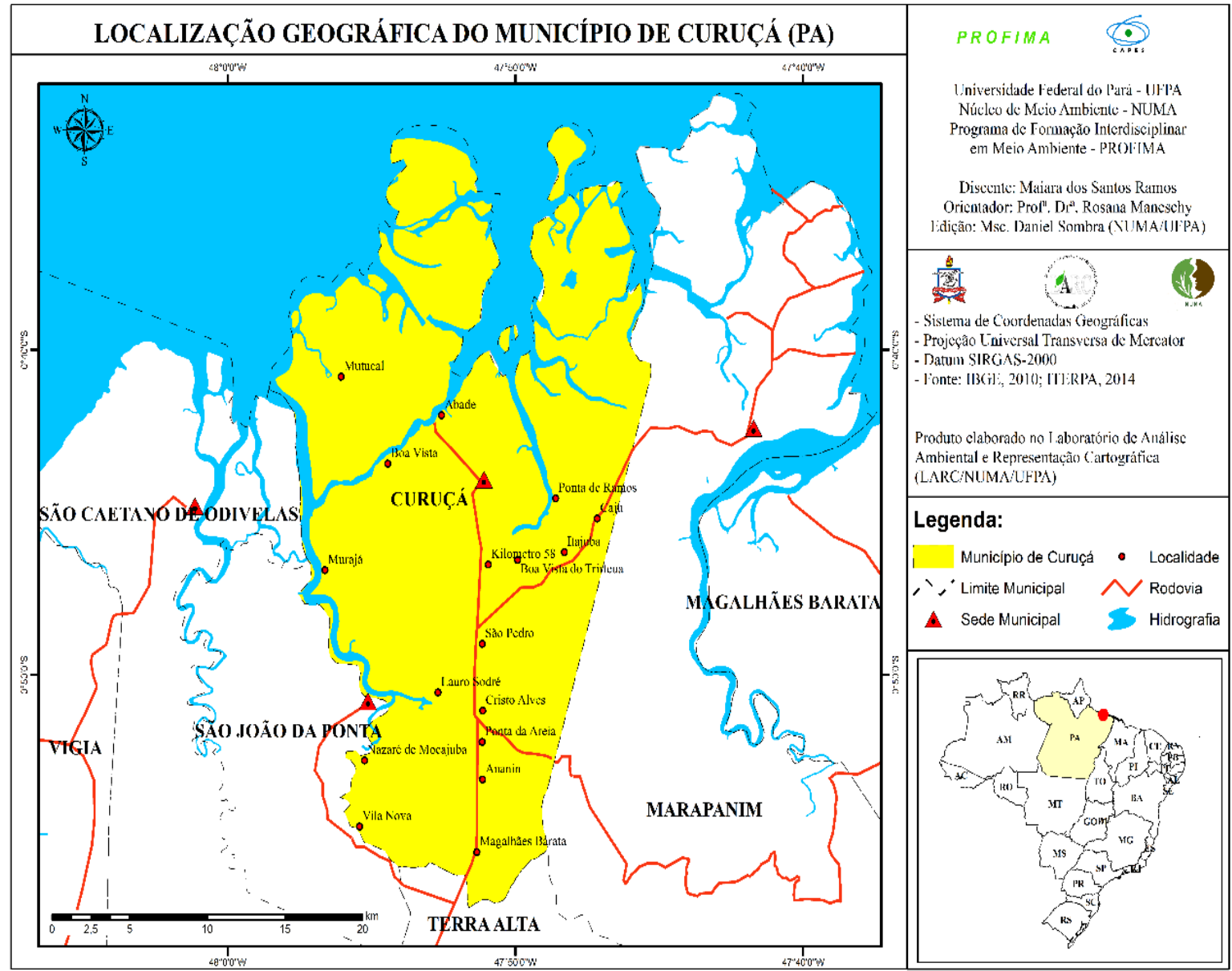

Fonte: Elaborado pelo Laboratório de Análise Ambiental, e Representação Cartográfica (LARC/NUMA/UFPA) Ano 2017.

\section{RESULTADOS E DISCUSSÃO}

De acordo com FNDE foram

repassados valores para o município para o Programa Nacional de Alimentação Escolar (Tabela 1).

Tabela 1. Evolução do PNAE no município de Curuçá 2012 a 2015.

\begin{tabular}{ll}
\hline Ano & Valor (R\$) \\
\hline 2012 & \\
2013 & $2.240,00$ \\
2014 & $3.180,00$ \\
2015 & $3.500,00$ \\
\hline
\end{tabular}

Fonte: Autor próprio com dados do Fundo Nacional do Desenvolvimento e Educação (FNDE) - Ano de 2010. 
Os entrevistados são proprietários de áreas que variam de pequeno a grande porte (3 hectares a 70 hectares), sendo utilizado também como moradia. Em relação a mão-de-obra utilizada todos os produtores relatam utilizar mão-de-obra familiar e também necessitar de mão-deobra temporária. Na ausência por alguma eventualidade, a maioria conta com a ajuda dos parentes e filhos. Os filhos são incentivados pelos pais a estudarem em busca de melhores condições de vida.

Percebeu-se considerável a presença de agricultores que variam de 32 a 45 anos, quanto à escolaridade boa parte estudou até o ensino médio incompleto, começaram as atividades agrícolas através de incentivos dos pais para a contribuição na renda familiar, esse foi uns dos motivos para a não conclusão dos estudos.

A associação entrevistada foi a Associação de Produtores e Produtoras Rurais de Acaputeua, sua criação foi através de incentivos da EMATER para a organização e fortalecimento de seus produtos no comercio local, gerando assim mais oportunidades para a participação de programas do governo. E assim, de acordo com Villa Real e Schneider (2011) as políticas públicas, tais como Programa de Alimentação Escolar possa sim, produzir "mudanças positivas tanto na produção quanto no consumo de alimentos na sociedade contemporânea, bem como contribuir para 0 desenvolvimento com sustentabilidade". Com reflexos ambientais para a sociedade local, bem como para a "qualidade de vida dos agricultores familiares e dos alunos beneficiados com o programa" (FERIGOLLO et al., 2017).

Em relação ao transporte existe um fornecido pela associação e outro pela prefeitura para o escoamento de seus produtos, todos em boas condições de uso, com estradas regulares.

Em relação ao Programa Nacional de Alimentação Escolar, todos gostariam de participar, mas para isso precisam de um excedente maior, além de adequações na propriedade, como mais investimentos, entretanto, o agricultor não dispõe de recursos financeiros, e para tanto, diz ser muito difícil obter financiamento do PRONAF devido à burocracia do governo. 
Vale lembrar que em 1995, o governo federal criou o PRONAF (Programa Nacional de Fortalecimento da Agricultura Familiar), sendo este, fruto de ação/reivindicação dos agricultores familiares, conquistada através do \| GRITO DA TERRA BRASIL. Os critérios para a classificação do público beneficiários do PRONAF foram: a) agricultores (proprietários, arrendatários, parceiros e ocupantes) com menos de 4 módulos fiscais; b)utilização de trabalho direto familiar; c) emprego eventual ou ajuda de terceiros, quando a natureza da atividade sazonal ou exigir; d) não utilizar serviços de empregados permanentes; e) no mínimo $80 \%$ da renda familiar deveriam ser originário da exploração agropecuária; f) residência na propriedade ou em aglomerado rural ou urbano próximo (GONÇALVES, 2008, p.13-14).

Quadro 3. Espécies cultivadas pelos agricultores familiares no município de Curuçá, PA.

\begin{tabular}{|l|l|}
\hline Espécie & Nome científico \\
\hline Açaí & Euterpe oleracea \\
\hline Acerola & Malpighia emarginata \\
\hline Alface & Lactuca sativa \\
\hline Bacuri & Platonia insignis \\
\hline Banana & Musa sp. \\
\hline Cana-de-açúcar & Saccharum officinarum \\
\hline Couve & Brassica oleracea \\
\hline Cupuaçu & Theobroma grandiflorum \\
\hline Feijão de verde & Vigna unguiculata \\
\hline Macaxeira & Manihot esculenta \\
\hline Maracujá & Passiflora edulis \\
\hline Pepino & Cucumis sativus \\
\hline Tomate & Solanum lycopersicum \\
\hline
\end{tabular}

Fonte: Autor próprio com base nas entrevistas aos agricultores do município de Curuçá-Ano 2017.

Em análise as entrevistas, observou o interesse dos agricultores a participarem do PNAE, os desejos de aumentar a produção, tanto em quantidade como 
qualidade e variedade, entretanto, alegam falta de investimentos em suas propriedades, por dificuldade em obter financiamentos, as razões, são burocracia na documentação, falta de informação. Todos possuem equipamentos básicos para trabalharem, atribuindo dificuldade em aquisição de novos equipamentos.

EMATER foi lembrada por todos os agricultores entrevistados como sendo a prestadora de orientação técnica, um falou da presença da vigilância sanitária, outro agricultor conta com a ajuda de um amigo agrônomo. Também foi mencionada pelos agricultores, a importante contribuição do SENAR (Serviço Nacional de Aprendizagem Rural) com incentivos a realização de cursos oferecidos, o que suprido suas necessidades para melhorar suas produções.

Em relação à produção agrícola do município de acordo com o extensionista da EMATER, o município conta em média com 1200 agricultores identificados, mas apenas 195 são participantes do PNAE. Em relação à oferta e a demanda, o entrevistado admiti existir necessidade de aumentar a oferta de produtos da agricultura familiar.

De acordo com o extensionista, para fortalecer ou incentivar a participação dos agricultores no Programa de Alimentação Escolar, a expectativa consiste em criação de novas associações, sendo que o município conta apenas com uma única associação que denomina o mercado do PNAE. A solução seria trabalhar com mais associações espalhadas por setores dominados por hortifrutigranjeiros. Ressalta-se que na visão da Secretaria Municipal da Agricultura de uma maior organização social, no cooperativismo e no associativismo, dessa forma fortalecendo o meio produtivo e criando mais oportunidades para financiamentos.

O município de Curuçá conta somente com uma nutricionista, o que é exigido pelo Programa para a elaboração do cardápio escolar. Atuante no município apenas três meses, e, de acordo com ela, o município não participa do PNAE, apenas do PAA (Programa de Aquisição de Alimentos), aonde desenvolve o cardápio para as escolas do município. A mesma admite que no município o número de agricultores é grande, porém a falta de organização por 
parte deles e a variedade de alimentos ser pequena, acabam dificultando o acesso ao programa do PNAE. Devido seu pouco tempo no município e na área de atuação, não possuir conhecimentos suficientes das necessidades das escolas, estando em período de adaptação.

Portanto, percebe-se que apesar do município possuir grande número de agricultores e os gestores empreendam esforços em adequar a oferta de produtos da agricultura familiar na merenda das escolas, ainda assim existe um longo caminho a ser percorrido, e principalmente na falta de informações entre os envolvidos na alimentação escolar. Braga e Azevedo (2012) ressaltam que a falta de políticas intersetoriais na gestão municipal e a participação ativa da sociedade civil no processo de aquisição de alimentos pode ser o maior entrave para a adoção do PNAE.

As atividades agrícolas no município de Curuçá são divididas de duas formas, de ciclo produtivo: Lavouras permanentes (Tabela 2) e temporárias (Tabela 3). De acordo com o IDESP (2015) Curuçá possui o seguinte panorama agrícola apresentando nas tabelas abaixo: Dados são baseados de acordo com $\bigcirc$ Fundo Nacional de Desenvolvimento da Educação (FNDE) para descrever os alimentos produzidos pelos agricultores do município de Curuçá.

Na atualidade o município de Curuçá conta com sessenta e sete escolas (Tabela 4), o município também conta com uma creche municipal, que atende alunos oriundos de famílias locais de baixa renda.

Tabela 2. Produtos das Lavouras Permanentes no ano de 2015, Curuçá- PA.

\begin{tabular}{lcccr}
\hline Produtos & Área colhida (ha) & Quant. Produzida (t) & \multicolumn{2}{c}{ Valor (mil reais) } \\
\hline Banana & 9 & 108 & $\mathrm{R} \$$ & 76 \\
Coco da baía & 160 & 1600 & $\mathrm{R} \$$ & 720 \\
Dendê & 80 & 1286 & $\mathrm{R} \$$ & 334 \\
Laranja & 12 & 108 & $\mathrm{R} \$$ & 64 \\
Limão & 5 & 50 & $\mathrm{R} \$$ & 34 \\
Mamão & 25 & 375 & $\mathrm{R} \$$ & 334 \\
Maracujá & 210 & 3.150 & $\mathrm{R} \$$ & 2.678 \\
Pimenta-do-reino & 240 & 480 & $\mathrm{R} \$$ & 14.400 \\
Urucum & 8 & 5 & $\mathrm{R} \$$ & 20 \\
\hline
\end{tabular}

Fonte: Fundo Nacional do Desenvolvimento e Educação (FNDE)-Ano 2010. 
Tabela 3. Atividades Agrícolas Temporária no ano de 2015, Curuçá - PA.

\begin{tabular}{lcccr}
\hline Produtos & Área colhida (ha) & Quant. Produzida (t) & \multicolumn{2}{c}{ Valor (mil reais) } \\
\hline Abacaxi (frutos) & 40 & 800 & $\mathrm{R} \$$ & 960 \\
Feijão grãos & 50 & 40 & $\mathrm{R} \$$ & 39 \\
Mandioca & 800 & 16.000 & $\mathrm{R} \$$ & 2.880 \\
Melancia & 70 & 42 & $\mathrm{R} \$$ & 1.280 \\
Milho & 80 & 1286 & $\mathrm{R} \$$ & 19 \\
\hline
\end{tabular}

Fonte: Fundo Nacional do Desenvolvimento e Educação(FNDE)-Ano 2010

Tabela 4. Alunos beneficiados por alimentos da agricultura familiar, Curuçá - PA.

\begin{tabular}{l|c}
\hline Alunos & Quantidades \\
\hline Creche & 102 \\
Pré-escola & 1045 \\
Fundamental & 5035 \\
Médio & - \\
Fundamental (EJA) & 121 \\
Médio (EJA) & - \\
EEA & 37 \\
\hline Total & 6340 \\
\hline
\end{tabular}

Fonte: Fundo Nacional de Desenvolvimento da Educação (FNDE)-Ano2010.

Os agricultores declararam que o fator principal limitante ao PNAE, seriam as dificuldades encontrados para a obtenção de financiamento, devido a burocracia na documentação exigida, falta de informação. Através do financiamento seria capaz de investir mais em suas propriedades, dessa forma suprindo a demanda dos produtos agrícola do município. As associações produzem grandes quantidade de hortaliças, como: Alface, couve, cebolinha, chicória, cheiro verde. Outro fato citado, é que a população não tem como habito comer saladas, e os produtores precisam ser vendidos em outros locais como na feira de Castanhal e no CEASA (Centro de Abastecimento do Pará). Segundo Gavioli (2001) e à conservação dos recursos naturais, para que isso de fato funcione os agricultores necessitam de assistência técnica que viabilize a produção afinada com o uso sustentável dos recursos naturais.

A DAP foi criada para identificar e qualificar o agricultor familiar e permitir 
acesso diferenciado às políticas públicas. Atualmente a DAP concede acesso a mais de 15 políticas públicas, dentre elas o crédito rural do Programa Nacional de Fortalecimento da Agricultura Familiar (Pronaf), os programas de compras institucionais, como Aquisição de Alimentos (PAA) e o de Alimentação Escolar (PNAE), a Empresa de Assistência Técnica e Extensão Rural (EMATER-PA), o programa Garantia Safra e o Seguro da Agricultura Familiar. Essas políticas públicas alinhadas e com uma política municipal intersetorial que apoiem as ações, podem configurar de fato o PNAE como um programa que leve ao incentivo da produção agropecuária local, melhoria da qualidade de vida dos agricultores e consequentemente contribuir para $\mathrm{O}$ desenvolvimento local (HONDA et al. 2016; SANTANA et al., 2017; SCHRÖDE, 2010).

Na consulta realizada ao site do MDA, em seu banco de dados, obtiveram como resultado quatro associações, bem como, o número de associados ativos e inativos (Tabela 5).

Tabela 5. Associações no município de Curuçá - PA.

\begin{tabular}{|c|c|c|c|c|}
\hline Associações & DAP & Sem DAP & $\begin{array}{l}\text { Quantidade de } \\
\text { Associados }\end{array}$ & Ativas \\
\hline $\begin{array}{l}\text { Associação dos Trabalhadores e } \\
\text { Trabalhadoras Rurais da Via de } \\
\text { Mutucal }\end{array}$ & 2 & 45 & 47 & Não \\
\hline $\begin{array}{l}\text { Associação dos Usuários da } \\
\text { Reserva Extrativista Mãe Grande } \\
\text { de Curuçá }\end{array}$ & 3 & 16 & 19 & Não \\
\hline Associação de Mulheres de Murajá & 3 & 47 & 51 & Não \\
\hline $\begin{array}{l}\text { Associação dos produtores e } \\
\text { produtoras Rurais de Acaputeua }\end{array}$ & 19 & 5 & 24 & Sim \\
\hline
\end{tabular}

Fonte: Secretaria da Agricultura Familiar e do Desenvolvimento Agrário-2010.

\section{CONCLUSÃO}

São vários os problemas enfrentados pelo agricultor familiar local, a começar pela falta de financiamento em suas propriedades, falta de diversidade de produtos, entre outros. A dificuldade está relacionada também com falta de informações sobre o PNAE.

Considerou-se também um fator limitante, pouca troca de informações entre 
as partes envolvidas, pois se acredita que o agricultor informado sobre comercialização, tais como preços praticados, condições de mercado, consumo, qualidade, demandas, entre outras. Importante ressaltar ainda, o Programa de Alimentação Escolar requer uma organização mínima de todos os envolvidos, ou seja, dos agricultores familiares às instituições locais, entretanto, aos agricultores relataram carência em relação a presença de gestores, ocasionado assim, desinformações.

Outro fator limitante seria o município possuir apenas uma associação, acabam limitando quanto a quantidade, variedade de produtos entregues para alimentação escolar do município. O mesmo possui um grande número de agricultores, porém não organizados, produzem principalmente para subsistência de sua família.

Nesse contexto, para o município de Curuçá participar do Programa Nacional de Alimentação Escolar, seria necessário primeiramente $\mathrm{o}$ fortalecimento da agricultura familiar no município, através do cooperativismo. Dessa forma aumentar o poder de barganha através do aumento do volume, da qualidade, da diversidade, da regularidade e eficiência nos prazos determinados. Se contar que através do cooperativismo, poderão ser superadas algumas limitações, a começar pela dificuldade de acesso a linhas de credito adequadas a realidade desses agricultores, a falta de maiores incentivos para a melhoria das propriedades e consequentemente $\mathrm{O}$ aumento da produção diversificada.

Dessa forma, havendo possibilidades para geração de empregos e renda nas propriedades rurais locais, contribuindo desta maneira para um aumento da oferta aos consumidores locais de produtos diversificados e de qualidade nutricional, oriundos da agricultura familiar. Acredita-se ainda, na possiblidade de obter através dessas ações, a conscientização das populações locais em geral, da importância social, ambiental, econômica e cultural ao optarem pelos produtos produzidos localmente.

\section{REFERÊNCIAS}

AÇÃO FOME ZERO. O que é o PNAE? Prêmio gestor eficiente da merenda escolar 2013. Disponível em: <http://uww.acaofomezero.org.br/premio/ midiateca/Paginas/pnae. aspx>. Acesso em: 20 abril 2017. 
BRAGA, E. M. F.; AZEVEDO, H. S. Segurança alimentar e nutricional: os desafios da intersetorialidade. Revista Aval, v. 2, n. 10, p. 57-71, Jul/Dez, 2012.

BRASIL, Constituição (1988). Artigo 208, inciso IV e VII. Capitulo III. Seção I. Brasília: Senado Federal, 2006, p. 134.

CARVALHO, D. G. de; CASTRO, V. M. de. Programa Nacional de Alimentação Escolar como Política Pública de Desenvolvimento Sustentável. Anais... 8 ENCONTRO DA SOCIEDADE BRASILEIRA DE ECONOMIA ECOLÓGICA - ECOECO, 2009, Cuiabá-MT. Aplicando a Economia Ecológica para o Desenvolvimento Sustentável, 2009.

FERIGOLLO, D.; KIRSTEN, V. R.; HECKLER, D.; FIGUEREDO, O. A. T.; PEREZCASSARINO, J.; TRICHES, R. M. Aquisição de produtos da agricultura familiar para alimentação escolar em municípios do Rio Grande do Sul. Rev. Saúde Pública, São Paulo, v. 51, p. 1-10, 2017.

FUNDO NACIONAL DE DESENVOLVIMENTO DA EDUCAÇÃO FNDE. Disponível em: <http://www.fnde.gov.br>. Acesso em 11 de abr. 2017.

GAVIOLI, F. R. Multifuncionalidade da Agricultura e Território: notas a partir de um estudo no assentamento Monte Alegre. Campo-Território, v. 6, n. 11, 2011.

GERHARDT, T. E.; SILVEIRA, D. T. (org.). Métodos de pesquisa. Porto Alegre: Editora da UFRGS, 2009, 120p.

HONDA, Y. F.; GOMES, S. C.; CABRAL, E. R. Participação dos produtores familiares no PAA: estratégias de produção e comercialização em área periurbana do município de Ananindeua, PA. Revista Cesumar Ciências Humanas e Sociais Aplicadas, v.21, n.1, p. 125-145, jan./jun. 2016.

INSTITUTO BRASILEIRO DE GEOGRAFIA E ESTATISTICA-IBGE-censo2010. Disponível em: < http://censo2010.ibge.gov.br/>. Acesso em: 10 maio 2017.

SANTANA, A. C. de; SEQUEIRA, G. R.; OLIVEIRA, C. M. de; GOMES, S. C. Mercado institucional e agricultura urbana e periurbana em Curuçambá, Ananindeua, Pará: Oportunidades e desafios. G\&DR, v. 13, n. 1, p. 316-338, jan-abr/2017.

SCHRÖDE, M. Desenvolvimento rural, meio ambiente e políticas públicas: os caminhos do fortalecimento da agricultura familiar na Amazônia brasileira. PRACS, n. 3, p. 53-69, dez. 2010.

SPINELLI, M. A. dos S.; CANESQUI, A. M. O programa de alimentação escolar no estado de Mato Grosso: da centralização à descentralização (1979 - 1995). Rev. Nutr. v.15, n.1 Campinas Jan. 2002.

TEO, C. R. P. A.; MONTEIRO, C. A. Marco legal do Programa Nacional de Alimentação Escolar: uma releitura para alinhar propósitos e prática na aquisição de alimentos. Rev. Nutr. v. 25, n. 5 Campinas Sept./Oct. 2012.

VILLA REAL, L. C.; SCHNEIDER, S. O uso de programas públicos de alimentação na reaproximação do pequeno produtor com o Consumidor: o caso do programa de alimentação escolar. Estudo \& Debate, Lajeado, v. 18, n. 2, p. 57-79, 2011. 